\title{
Distance Learning in Moroccan Higher Education: Students' Attitude towards ENS -Ecole Normale Superieure - Classroom Platform and Effective Recommendations
}

\author{
Mohamed Merouane El Hammoumi ${ }^{1, *}$, Safaa El Youssfi ${ }^{2}$ \\ ${ }^{1}$ Bio-Geosciences and Material Engineering Laboratory «LBGIM» Ecole Normale Superieure, Hassan II University, Casablanca, \\ Morocco \\ ${ }^{2}$ American Language Center (ALC-Fes), Fes, Morocco
}

Received October 27, 2020; Revised December 9, 2020; Accepted December 30, 2020

\section{Cite This Paper in the following Citation Styles}

(a): [1] Mohamed Merouane El Hammoumi, Safaa El Youssfi , "Distance Learning in Moroccan Higher Education: Students' Attitude towards ENS -Ecole Normale Superieure - Classroom Platform and Effective Recommendations," Universal Journal of Educational Research, Vol. 8, No. 12B, pp. 8478 - 8487, 2020. DOI: 10.13189/ujer.2020.082657.

(b): Mohamed Merouane El Hammoumi, Safaa El Youssfi (2020). Distance Learning in Moroccan Higher Education: Students' Attitude towards ENS -Ecole Normale Superieure - Classroom Platform and Effective Recommendations. Universal Journal of Educational Research, 8(12B), 8478 - 8487. DOI: 10.13189/ujer.2020.082657.

Copyright $\bigcirc 2020$ by authors, all rights reserved. Authors agree that this article remains permanently open access under the terms of the Creative Commons Attribution License 4.0 International License

\begin{abstract}
Distance learning is developing at high speed in Morocco as well as in the rest of the world. With the inability to move from home due to the COVID 19 outbreak, it may seem obvious that it represents a solution and a good way to develop skills and knowledge and to guarantee academic continuity. As we live now in a society with constant social and cultural change, information and communication technologies have been contributing towards the construction of a new kind of society- the information society, where students need to be equipped with skills to do research, analyse and select knowledge from different paths and digital resources [1]. So, the purpose of this study is to find out about Moroccan university students' attitudes towards ENS Classroom platform which they have been using during quarantine and how they are discovering distance learning for the first time. The study revealed that although the platform has truly enabled them to overcome the distance that separates students from the university, a set of challenges appeared during their e-learning courses and hindered the best understanding and retention of the course content. The results are significant since they show how unsatisfied ENS students are towards their distance learning experience. The study also suggests a set of recommendations to cater
\end{abstract}

for better academic outcomes.

Keywords Distance Learning, Digital Platforms, Attitudes, ICT

\section{Introduction}

The entire world has been widely affected by the Coronavirus pandemic, which pushed most governments around the world to close schools and universities temporarily and put an end to face-to-face courses and replace them with distance courses, with the aim of ensuring the continuity of academic programs and containing the spread of the virus. In this respect, the Moroccan government released a statement announcing its decision to suspend all school activities until further notice due to the spread of the novel coronavirus, known officially as COVID-19. The closure has also affected training centers, public, and private schools, and took effect on Monday, March 16, 2020.

Distance learning in education has become a necessity now more than any time. There is a growing need of it 
especially in periods of crises. Online courses bring a lot of ecological, economic and academic benefits. The learner does not need to travel to the school to take courses. All one needs is an internet network from a laptop, a tablet, or a smartphone. Students can manage their time, and can take their courses remotely at any time.

Since the outbreak of COVID 19, giving the fact that Morocco has never had the experience of distance learning, the Moroccan government, therefore, has been putting a lot of efforts and trying to improve e-learning. Recommendations and solutions have been developed to improve the students' learning across the country. Accordingly, the ministry of education has implemented digital platforms (Microsoft teams and classrooms), television broadcasts and a set of teaching materials to rural students.

The issue which rises is whether teachers and students are equipped with the necessary pedagogical and technical skills to shift from in-class to virtual education. For distance, learning to take place successfully, a number of measures and conditions should be taken into consideration. In reality, the majority of Moroccan families, especially those who have more than one child, have been facing a serious challenge trying to manage their children's online courses that take place at the same time. A lot of problems are related to internet connectivity, connection access, and digital devices. After a whole trimester of online courses, this study tries to shed light on distance learning in Moroccan universities, especially at ENS (Ecole Normale Supérieure), Casablanca.

The ultimate focus of this study is on the ENS students' attitudes towards distance learning in general and ENS Classroom (a digital platform created by ENS, Hassan II University, Casablanca) in particular. This study falls into two major parts. The first part gives a general overview of distance learning and its challenges and also defines the ENS Classroom platform used for distance learning. The second part sets out to examine the extent to which students welcome or decline the idea of adopting e-learning in Morocco. This is achieved by analysing what has been gathered through a questionnaire administered to ENS students after completing the second term using ENS classroom and other digital platforms. The study ends with some concluding remarks and suggests a set of policy recommendations for a successful distance education.

\section{Literature Review}

\subsection{Distance E-Learning}

Distance e-learning is a type of online and distance training and education that uses the Internet and novel digital multimedia technologies such as CD ROMs, digital platforms, chatrooms, google products, etc. With the aim of continuing education and improving learning processes in case, learning in a traditional classroom setting is hard to attain, especially in periods of crises. This type of teaching allows learners to be able to learn and train remotely at home, whenever they wish, and to have access to different educational content whenever and wherever they are, and at their own pace.

E-learning is defined by [2] as an innovative, web-based system based on new digital technologies and other forms of educational tools whose ultimate goal is to provide students with a personalized, learner-centered, open, enjoyable, and interactive learning environment supporting and enhancing the learning processes.

According to [3], e-learning may be a solitary, individual activity, or a collaborative group activity. [3] also distinguishes between synchronous (real-time) and asynchronous (flexi-time) communication modes. So, learners and teachers in a synchronuous learning mode interact in a scheduled virtual place at a specific time, using specific digital tools such as video conferencing, electronic white boards, teleconferencing, live chatting, and live-streaming lectures. It requires learners to be present during content delivery [4]. Learners, in this respect, benefit from active engagement, immediate feedback, real-time discussions and interactions, and regular guidance and mentorship. On the other hand, in an asynchronuous learning mode, teachers usually set up a learning path, where students engage with at their own pace. It doesn't require learners to be present on spot. Learning can occur in different times and spaces particular to each learner [5]. Usually instructors choose this mode of learning due to a couple of technical problems such as audio or video troubleshooting and connection issues [5].

In the new e-learning environment, the roles of the instructors and the learners have undergone dramatic changes. The traditional classroom teacher becomes an online virtual instructor who is required to be equipped with a set of new technological and pedagogical skills and competencies. [6] states that the teacher's role is changing from importers of knowledge to expeditors of knowledge [7]. The online learner becomes a non-linear navigator through never-ending oceans of information, which also requires new skills and competencies [3].

\subsection{Challenges}

\subsubsection{Course Management}

Learning in total autonomy requires a certain degree of self-discipline. The e-learning environment involves students in continuing the educational process all the day and working week. Students are engaged in a wide spectrum of educational activities, which requires full focus and engagement. All things are scheduled, and learners just tide. E-learning offers more freedom for learners, but also requires planning of their own self-development and high self-discipline [8]. So if 
students, especially the youngest and teens, do not respect the instructor's rules regulating the virtual regular meetings, the e-learning experience ends up being worthless and fruitless. It means that self-discipline becomes highly important to ensure the learners' accomplishments and allow them to achieve their learning goals.

\subsubsection{Motivation}

In an e-learning context, students are far from their teacher. So, beside the usual difficulties (mental and physical readiness) students encounter in traditional classroom settings, they have different kinds of difficulties and barriers that may extinguish their enthusiasm and motivation to learn [9]. Learning on one's own is not necessarily motivating. Apart from those interactive games and activities, teachers use from time to time, and the lack of motivation is a recurring criticism made of digital training tools. So, in order to benefit from e-learning, the learner has to be highly motivated. Instrutors are in a continuous struggle to create modules, educational activities, and methods which are highly relevant, fun and engaging enough to capture the attention of the learners - either face-to-face or distance learning.

Another key factor that might affect students' motivation and attitudes towards distance learning is confidence in using the digital multiledia tools. Digital literacy is of crucial importance in this case. Learners as well as teachers need pre-education and training before starting the e-course [9].

\subsubsection{Access}

By definition, e-learning is a learning modality that requires access to computer tools and very often to an internet connection. If the learner does not have a computer, a mobile device or a suitable rapid connection, he/she will not be able to benefit from this experience. In addition, Instructors and learners do not properly master digital technology. The obligation to train on a digital platform can be experienced only as a constraint and a source of stress for both of them. E-learning is, therefore, a powerful learning tool that is revolutionizing the way of teaching and learning, the teaching aids, and pedagogy. In most developing and underdeveloped countries, COVID-19 has demonstrated the fragile infrastructure of education. Both teachers and students are not well-equipped with the tools and the skills to embrace this novel e-learning experience. This current inequalities or the digital devide are intensified. Moreover, the wealth gap exists for students who are poor within the University and find it difficult to afford adequate computers and Internet at home. So, it becomes even hard to ensure that all students have equal access to distance learning.

The attempt to shift university education online during the coronavirus pandemic has amplified inequality in access to education in Morocco in particular and other parts of the world in general, sharpening the distinction between those students who have high-speed access to the Internet and to phones, tablets, and laptops and those refugees, children of the poor, residents of rural areas, females in socially conservative families who are getting weaker access, if they have access at all due to the high cost of access that become a financial burden on the families shoulders [10]. It has been confirmed by [10] that UNESCO has sounded the alarm about the attempted global shift to online education and that 826 million students globally do not have computers of their own and 48 percent of households in the Arab world do not have home Internet connection. Similarly, [11] states that COVID-19 has demonstrated the current inequalities in the system and suggests the need for universal and low-cost access to the Internet for education.

\subsubsection{Learning styles}

It has been noted by [12] that in order to attain the best learning results, it is advisable to understand deeply different students' learning styles. Online students' learning styles can be ambiguous. Some students learn through physical interaction and movement (kinesthetic), some prefer visual learning through visual presentations, and others are auditory as they learn better by listening to instructions and using written notes. This challenge poses a serious issue for academics to understand and implement the learning styles of their students in an e-learning environment.

To conclude, [13] declares that teachers dealing with differences in students' attitude, motivation, and learning style do not work well in the e-learning environment. This failure of distance learning in developing and underdeveloped countries cannot be attributed to e-learning itself, but to the fact that the potential of this teaching method has been underestimated and excluded from the digital education projects of educational organizations and systems in these countries [14]. Hence, The future of e-learning must be built on principles of fairness, equality, sustainability, and a deep understanding of the sociocultural, personal, and academic potentials of the learner.

\section{ENS Classroom: A New E- Learning Platform at ENS, Casablanca}

The world in general and Morocco in particular has undergone a process of digital transformation of its teaching practices and learning models since the outbreak of the COVID-19 pandemic. Therefore, digital learning becomes a necessity now more than any time before because it offers digital educational multimedia tools for the benefit of students, thanks to which the learning objectives can be achieved in a simpler, more fluid, and efficient manner. Digital Learning is involved in both 
face-to-face and distance learning.

Accordingly, Hassan 2 University, Casablanca offered various platforms which help in transforming the way students learn today. These platforms have evolved enormously in order to provide an active, engaging experience for both students and teachers. The university crowns its experience in this area by organizing the Digital Day each year. Conferences and workshops are scheduled to debate the issues of these educational and technological advances and their impact on the process of innovation in our teaching and knowledge transfer methods. ENS classroom was created by Ecole Normale Superieure, Casablanca to attain the best learning outcomes in this high period of crisis. This digital platform offers a variety of resources and activities such as video conferencing, a chatroom, workshops, ebooks, feedback, tests and lessons.

\section{Research Methodology}

A questionnaire and an online interview were used as research methods to obtain information about the attitudes of ENS students towards distance learning and their experience with ENS classroom, and the extent to which they were satisfied with e-learning in general and the platform in particular. It was also carried out to come up with an e-learning framework that opens a room for alternative solutions to cater for the best learning results. The questionnaire was distributed amongst the under graduate and master students. Interviews were conducted with the same students. A hundred (100) digital copies of the questionnaire and the interview questions were sent in Google forms via whatsapp to students from different levels (physics and chemistry major, science major), and 60 students responded, having a response rate of $60 \%$. A brief introduction informed the participants about the objectives of the study.

The questions were arranged in a way that gives maximum results. All questions were close-ended since they are easier to answer, to code, to enter and to be analyzed [15]. They can be more reliable and of great use analytically. A quantitative analysis of the data was carried out. It analyzed by using descriptive statistics Focus was given mostly to striking figures which are considered more important for this study. A qualitative analysis of the data collected from the interviews was also carried out. To respond the questionnaire's close questions, the respondents had to identify their geographical location during the lockdown, the devices and the digital applications used for their distance learning courses, the time they spent for distance study, the problems they faced and their attitudes towards the platform used in their school in particular and distance learning in general. During the interview, the respondents had to specify other problems they faced apart from the ones they checked in the questionnaire. They also suggested recommendations for a better e-learning experience.

\section{Survey Questionnaire Findings: Graphical Presentation and Analysis}

The first section provides some background information about the respondents. It is made up of three items, and the first item provides information about the sex of the respondents. Chart 1 clearly shows that a high percentage of respondents are female. This is because the majority of ENS undergraduate and graduate students are females.

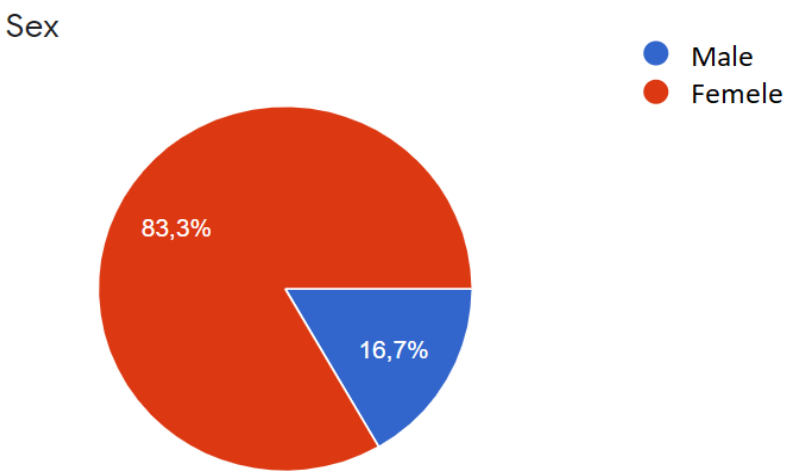

Chart 1. Sex

Level

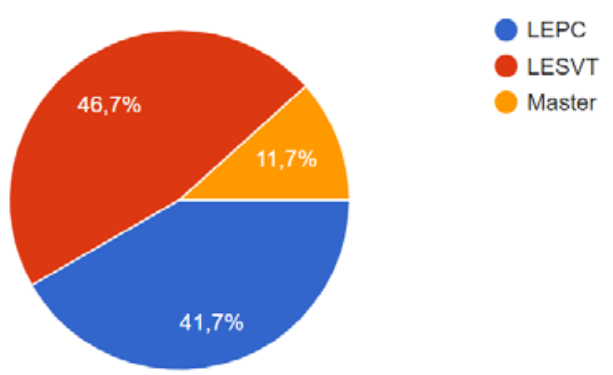

Chart 2. Students' level

The second item was designed to acquire information about the level or major of the respondents. It is clear in Chart 2 that the majority of respondents are undergraduate students coming from different majors (LEPC: Physics and chemistry undergraduate / LESVT: science undergraduate). 
Specify the geographical location
of the confinement

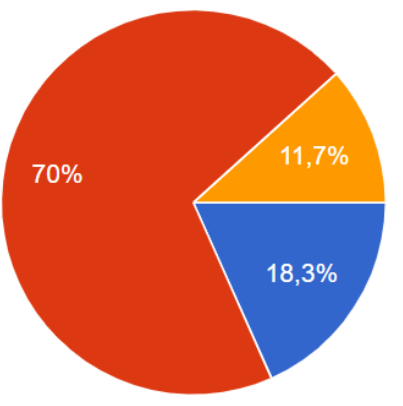

Chart 3. Location

Chart 3 displays that the respondents come from urban areas. Only a few of them originate from the countryside.
Rural

Urban

Semi-urban
How do you connect to the
distance course?

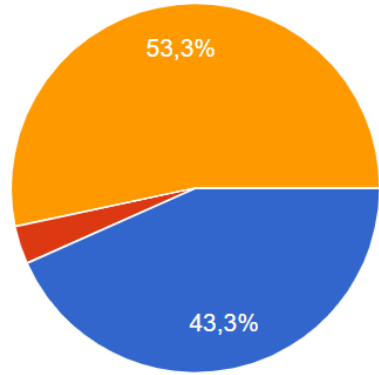

Chart 4. Tools used to connect to the e-course.

The next main question was regarding the digital devices students using to connect to the online course. Chart 4 indicates that students use the latest technological tools for their online class. More than half of them (53, 3\%) use their smartphones to $\log$ in, and the majority (43, 3\%) has laptops.

To connect you use
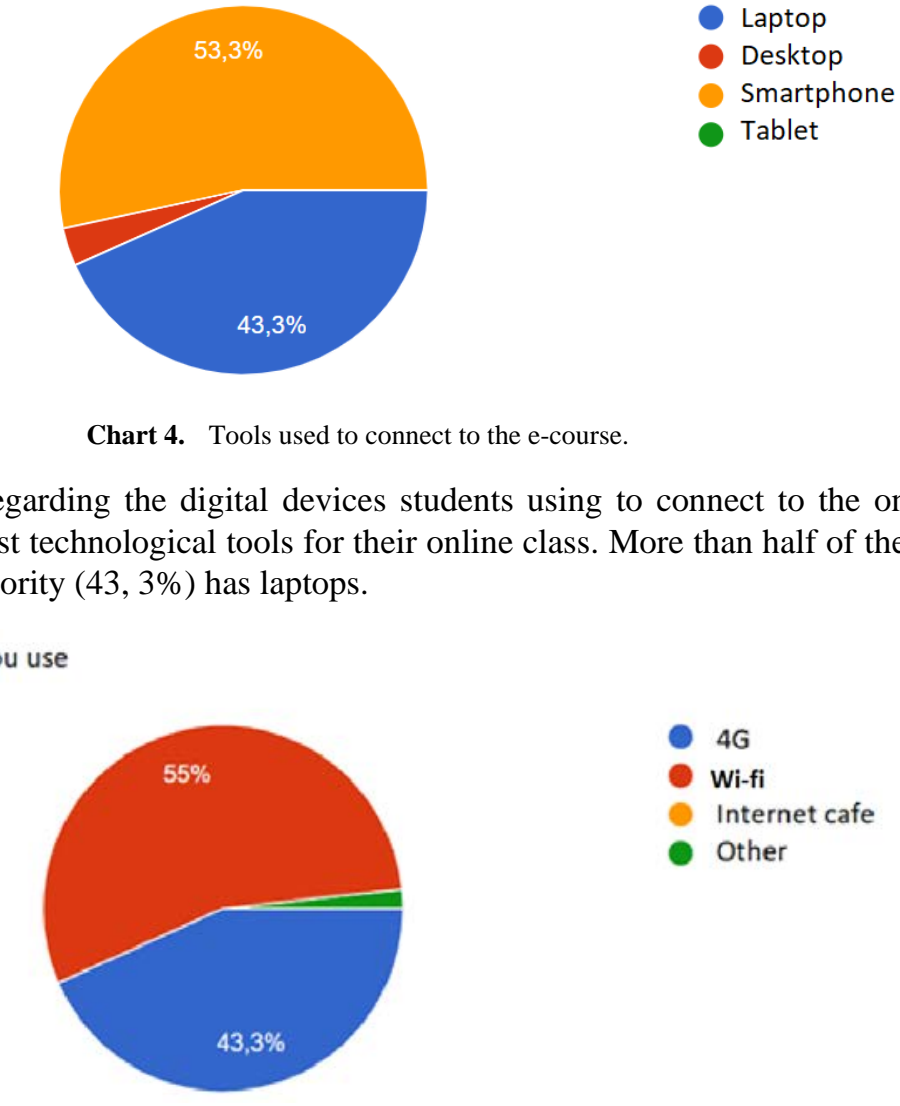

Chart 5. Internet connection

The figures in the above pie chart show that the majority of the respondents have wireless fidelity (Wi-Fi) connection at home and $43.3 \%$ of students use $4 \mathrm{G}$ that allows Internet access at a much higher speed, which means that nearly all students do not have problems of internet access which allows them to access their learning content. 
During your studies, what applications did you use for your distance education?

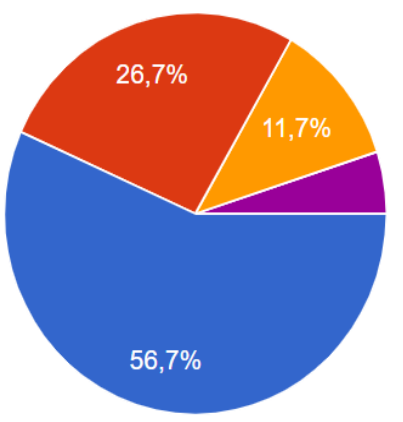

ENS Classroom
Whatsapp
Zoom
Skype
Google
Google classroom
Other

Chart 6. Applications used by students for distance learning

According to chart 6, ENS classroom is the application which is most used synchronously and asynchronously by the respondents because it is the official platform which ENS teachers use and which the school has created. Since this platform is used for the first time and both the teachers and the students were void of a prior training on how to use it and how to fully benefit from it, other social network applications were chosen in the meantime. WhatsApp was used synchronously and asynchronously to enhance online learning as it is easy to use, and it allows different contents to be shared such as pictures, pdf documents and videos. Moreover, users can send instant written and audio messages and check if the messages have been received properly and read by the receiver. Most teachers find it less costly and practical to use because they can address individual needs, communicate different messages related to assignment deadlines and instructions, course updates, announcements, and notices; and discuss the lesson content. Many students claim that they have been using the ENS classroom platform and WhatsApp at the same time, arguing that in ENS classroom, they can have access to course content with no explanation. The platform provides only a chatroom where they can exchange text messages with their professor. They confirmed that WhatsApp was a tool they know and like, and it was more helpful as it offers audio messaging. The instructors find it easy to share audio lessons, explanation, and feedback and receive audio comments from students.

On the one hand, zoom was not such a famous digital platform at ENS, Casablanca. Only $11.7 \%$ of the respondents use it. It was synchronously used for video conferencing by few instructors due to serious privacy and security concerns, setting that personal files like emails, videos, calls, and photos can be leaked.

The below chart (Chart 7) depicts the average time spent per day on distance learning. During the survey, learners (46.6\%) spend an average of 2 to 3 hours per day learning through digital products and platforms. It was also striking to notice that 20 percent of the respondents spend an average of 5 hours or more on the e-learning platforms. This shows that students need to increase their engagement, motivation and self-discipline to work in isolation. Distance learning for them is a new experience which they were not prepared for. They are used to learning in a face-to-face classroom, so it will definitely take time to adjust to the online learning experience. Here instructors should play a role in assisting them thrive in the new environment. 
What is the time spent per day for your distance study?

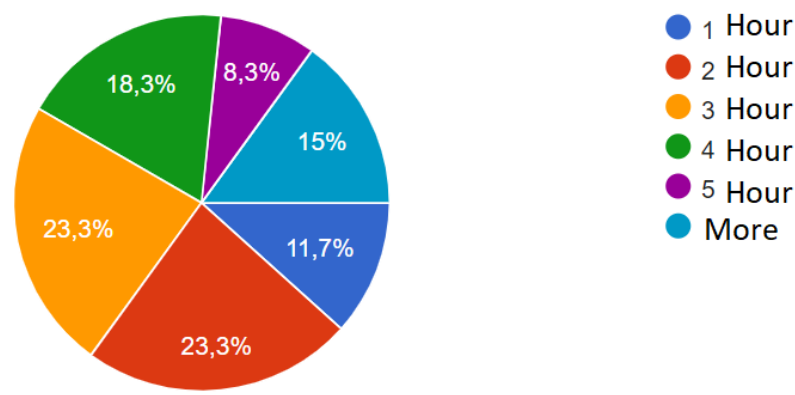

Chart 7. Time spent for distance learning

Among the technical problems, check the difficulties you have encountered.

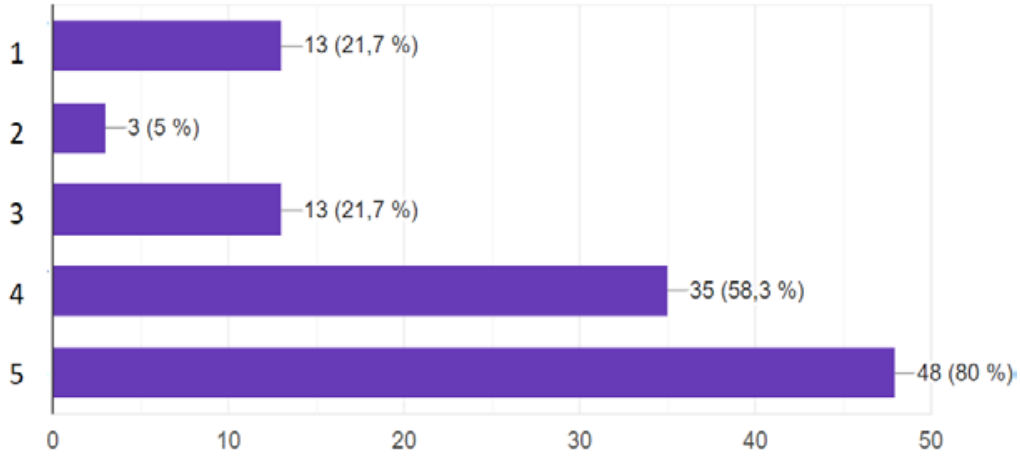

1. Slowness when uploading / downloading documents

2. Difficulty finding a course on the platform

3. Difficulty knowing how the platform works

4. Difficulty communicating with the teacher

5. Network slowness (WIFI / 4 G)

Chart 8. Technical problems

Giving the fact that 95 percent of the world's population lives in areas covered only by basic $2 \mathrm{G}$ cellular networks, according to 2016 data from the International Telecommunications Union [16], 80 percent of students have a very low-speed Internet access. Therefore, they simply can't use the distance learning teachers are working so hard to provide them with. This accessibility challenge will render most students unwilling to undergo such a learning experience.

Communicating with the teacher on the platform was another challenge 58.3 percent of students have. Isolation and lack of visual face-to-face contact contribute to the students' lack of engagement. The sense of community that is built in traditional classrooms is lacking in virtual ones, which broadens the gap between the learners and their instructors.

Confirming that ENS Students did not have the chance to benefit from pre-training sessions to know how to use the ENS classrooms platform, 21.7 percent of the respondents find it hard to use the various resources and activities the platform provides, apart from the lessons content which is easy to have access to.

Chart 9 demonstrates that ENS students are not really satisfied with the platform. They claimed that the quantity and quality of student teacher interactions and students' course content interactions are poor. Therefore, their learning environment lacks energy and classroom dynamics, and hence students' positive perception which [17] focuses on is not attained. There are a couple of elements which [18] identified and which affects the students' satisfaction such as learner relevance, active learning, authentic learning, learner autonomy, and technology competence. All these elements lacks in ENS e-learning environment. 


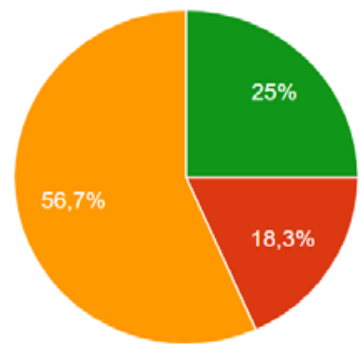

Very satisfied

Satisfied

a little satisfied

dissatisfied

Chart 9. The students' attitudes towards ENS Classroom

Are you going to continue to use ENS Classroom in the future?

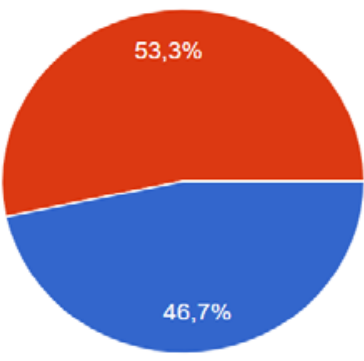

Yes

No

Chart 10. Using ENS Classroom in the future

Giving the fact that most students were not very satisfied with the platform, more than half of them are not going to continue using it in the future as it is clearly depicted in chart 10 . Ways to improve this online learning platform should be considered by academics and administrators of the school.

\section{Interview Findings}

\section{Question 1: What other problems have you encountered while studying online?}

Technical issues are one of the biggest obstacles which encountered nearly all ENS students. There are learners who do not know how to proceed due to the lack of prior training. Some of them even claim that their main problem is the poor functioning of the platform. Connection problems, difficulty accessing personal accounts on the platform, no free internet access to students from poor families, and difficulty using the platform resources (video conferencing, for example) are other challenges ENS students face during their e-learning experience. An interviewee states that ENS classroom provides a chatroom for the teachers to explain the lessons they post in the platform. However, this does not help the learners to understand and follow as messages pass quickly. And if the phone turns off, the entire teacher's chat is automatically erased, an interviewee confirmed which exacerbates frustration and lowers the students' motivation. These students see their learning experience interrupted and would likely end up dropping out of it.

A couple of interviewees argue that sometimes there can be some frustration among learners due to the lack of human relationships and the presence of their teacher, or the inability to interact with their classmates. This online world, as vast as it is, can sometimes be insufficient for the learners who want a physical space where they resolve their doubts or put their knowledge into practice through physical tools. These interviewees favor face-to-face learning rather than e-learning.

\section{Question 2: Do you have other recommendations for the support of your distance learning?}

One of the solutions which were suggested by most interviewees is to foster all personal interactions within the online world. Teachers can go beyond using ENS classroom platform and use various tools that allow more group interactions; they can organize webinars, group work sessions, or forums where students can discuss, understand more the lesson content, and dispel their doubts. It is essential that the learners have at their disposal a reference teacher with which to communicate (for example, through virtual courses and tutorials via Skype or Zoom). This is what an interviewee insisted on when saying that. There will be a need to have some improvement regarding student-teacher communication. It 
is better to provide direct and continuous communication and contact with teachers and not just send documents to the platform'.

It is also possible to encourage the use of social media networks (Facebook, messenger, WhatsApp, etc.) during e-learning in order to add another layer of social interaction and sense of community to the online learning. These apps and platforms, as a student states, make it easier for the teacher to teach and the students to learn so as to achieve common goals similar to classroom lessons.

Nearly all interviewees advocate the use of instructional videos which cater for the learning needs such as attention, understanding and retention. Videos, as an interviewee claims, make it possible to maintain one's attention. By applying both the visual and auditory canal differently, videos give a better understanding of the lesson content. Therefore, they strengthen memorization and retention.

Another interviewee highlights the importance of prior training for students and teachers to use the different techniques, applications and methods that facilitate distance study. Confidence while using the digital tools and the platform resources boosts students' motivation and positive attitude, and decreases anxiety.

\section{Recommendations}

Using hybrid digital tools which are more efficient and motivating, catering for more student /teacher and student/student interaction was highly recommended. In fact, students' motivation is an energising force for academic performance and achievement in higher education. So, this study will be helpful for academics and educational officials in developing countries to work on ways to improve e-learning platforms for the best educational results. Instructors need to have a clear vision on ICT in order to stimulate positive attitudes towards e-learning for positive learning targets.

Hence, a set of recommendations should be taken into consideration by policy makers. Because there is a lack of prior training on the skills required to access the distance learning platforms as it has been revealed by the respondents and confirmed by [18] in-service training on distance learning has become a requirement more than any time before. However, training of faculty and developing a good online platform are very expensive and time-consuming. Academics and students need to be trained on ICT. The training should not be through a theoretical overview, but through practical workshops, tutorials or guided video tours, which would help academics as well as students to be confident using the systems and the platforms. Students should be provided with tips on time management, self-discipline, goal setting, independent study and prioritizing work, and also on how to communicate and interact with their teacher and fellow students.

[19] has worked on a guide to design and develop an effective digital learning course in which it confirmed that the quality of an e-learning course is enhanced by the following criteria:

- Learner-centered content: The digital course curriculum must be precise and adapted to learner's needs as well as their professional duties and responsibilities.

- Granularity: The content of electronic learning must be segmented in order to facilitate assimilation and understanding of new knowledge and allow the time spent on learning to be adjusted.

- Stimulating content: Teaching techniques and methods should be used creatively in order to create a stimulating and motivating course for the learner.

- Interactivity: Frequent interactions with the learners are necessary to maintain attention and encourage learning. Instructors should work on building an online community because motivation and engagement increase when students feel a sense of belonging.

- Personalization: Self-study courses must be customizable to reflect the needs and the interests of the learners; by using tutorials, the trainer, tutor and / or facilitator must be able to monitor the progress and performance of individual learners.

Future online learning systems should encourage students' active participation and action taking and apply what they have learnt online. Teachers, on the other hand, need to provide regular constructive feedback which helps students feel a sense of progress and accomplishment.

Last but not least, e-learning should be an enjoyable experience for both instructors and learners. Online games, clubs, debates and forums can be created so that the students can get the maximum fun they need and the learning experience becomes amusing and motivating.

\section{Conclusion}

This study evaluates the efficiency of distance learning on a theoretical and an experimental basis. First, challenges that hinder an effective e-learning experience were analysed. These challenges are vital to understand for any institution wishing for a successful e-learning outcome.

The data collected reveal how unsatisfied ENS students are towards ENS platform used in their university. A set of challenges faced by these students were stated, most of which were technical. A similar study conducted by [20] reveals that there exists an absence of traces in the history of synchronous meetings, which indicates the learners' difficulties in communicating with each other, on questions relating to the course and in developing consistent collaborative work. [21] came to a conclusion that students generally have a low technology access. This is not a good enabler for successful implementation of 
ICT integration in teaching and learning.

Conclusively, this study provides opportunities for future research to be carried out on the effects of ENS Classroom on the students' academic achievement and the extent to which Moroccan university instructors are satisfied with distance learning. Future studies might also study if the academic and professional expectations of Moroccan university students are met from e-learning.

\section{REFERENCES}

[1] Figueiredo, J. \&Cardoso, S. 'Virtual digital environment in the Portuguese hospital schooling context: Perspectives of the health and education professionals', European Scientific Journal, vol.10, No.22, pp. 271 - 285, 2014.

[2] Rodrigues, H. Almeida, F., Figueiredo, V., \& Lopes, S. L. 'Tracking e-Learning through published papers: A systematic review', Computers and Education, Vol.136, No.1, pp. 87-98, 2019, doi:10.1016/j.compedu.2019.03.007.

[3] Romiszowski, A. 'How's the e-learning baby? Factors leading to success or failure of an educational technology innovation', Educational Technology, Vol. 44, No.1, pp. 5 27. 2004

[4] Khan, K.U. \& Badii, A. 'Impact of e-learning on higher education: Development of an e-learning framework', Life Science Journal, Vol. 9, No. 4, pp. 4073 - 4082, 2012.

[5] Finol, M. O. 'Asynchronous vs. synchronous learning: A quick overview', 2020, Retrieved from: https://www.brynm awr.edu/blendedlearning/asynchronous-vs-synchronous-lea rning-quick-overview.

[6] Harandi, S.R. 'Effects of e-learning on students' motivation', Procedia - Social and Behavioral Sciences, 3rd International Conference on Leadership, Technology and Innovation Management, Vol. 181, pp. 423 - 430, 2015, doi:10. 1016/j.sbspro.2015.04.905

[7] Matti, H. \& Reza, B. 'The Influence of Experience, Ability and Interest on e-Learning Effectiveness', European Journal of Open, Distance and E-Learning, No. 1, pp. 1-13, 2009, in https://eric.ed.gov/?id=EJ911761.

[8] Gorbunovs, A. \& et al., 'Self-discipline as a key indicator to improve learning eutcomes in E-learning Environment', Procedia -Social and Behavioral Sciences, International conference; Meaning in Translation: Illusion of Precision, Vol. 231, pp. 256 - 262, 2016, doi :10.1016/j.sbspro.2016.0 9.100 .

[9] Assareha, A. Hosseini Bidokht, M., 'Barriers to e- Teaching and e-learning', Procedia Computer Science, Vol. 3, pp. 791-795, 2011.

[10] Faek, R. \& Abd El-Galil, T. 'The shift to online education in
The Arab World is intensifying inequality, 2020, Retrieved from :https://www.alfanarmedia.org/2020/04/the-shift-to-on line-education-in-the-arab-world-is-intensifying-inequality.

[11] Bates, T. 'Crashing into online learning: A report from five continents And some conclusions', Tony Bates, 2020, Retrieved from:https://www.tonybates.ca/2020/04/26/crash ing-into-online-learning-a-report-from-fivecontinents-and-s ome-conclusions.

[12] Islam\& et al. 'E-learning challenges faced by academics in higher education: A Literature Review', Journal of Education and Training Studies, Vol. 3. No. 5, pp. 102 -112, 2015.

[13] Taylor, R. W., 'Pros and cons of online learning - A faculty perspective’. Journal of European Industrial Training, Vol. 26, No. 1, pp. 24-37, 2002, Retrived from http://dx.doi.org/10.1108/03090590210415876. doi:10.1108/03090590210415876.

[14] Valverde-Berrocoso, V. \& et al. 'Trends in Educational Research about e-learning: A systematic literature review' (2009-2018) Sustainability, Vol. 12, No. 5153, pp. 1 - 23, 2020.

[15] Hyman, R.M. \& Sierra, J.J. 'Open- versus close-ended survey questions’. Business Outlook. Vol. 14, N. 2. pp. 1- 5. 2016 Retrieved from https://www.researchgate.net/publicati on/282249876

[16] Rimmer, T. 'Tips on designing e-learning for folks with slow Internet', 2017, Retrieved from: https://community.articulat e.com/articles/tips-on-designing-e-learning-for-folks-with-s low-internet.

[17] Kuo, Y. C., Walker, A. E., Belland, B. R., \& Schroder, K. E.,'A predictive study of student satisfaction in online education programs', The International Review of Research in Open and Distance Learning, Vol. 14, No. 1, pp. 16-39, 2013. doi:10.19173/irrodl.v14i1.1338.

[18] Ke, F., \& Kwak, D. 'Constructs of student-centered online learning on learning satisfaction of a diverse online student body: A structural equation modeling approach. Journal of Educational Computing Research', Vol. 48, No. 1, pp. 97-122, 2013, doi: 10.2190/EC.48.1.e.

[19] Food and Agriculture Organization, 'Méthodologies pour le développement de cours e-learning Un guide pour concevoir et élaborer des cours d'apprentissage numérique', 2012, Retrieved from http://www.fao.org/elearning/Sites/ELC/Do cs/FAO_elearning_guide_fr.pdf

[20] Kaddouri, M. \& Bouamri, A., 'Usage de plateformes d'enseignement à distance dans l'enseignement supérieur marocain: avantages pédagogiques et difficultés d'appropriation', Open edition, Vol.7, No. 14, pp. 107-118, 2010, doi:10.4000/questionsvives.642.

[21] Wilson, K.B. \& et al. 'Information and communication technology use in higher education: Perspectives from students', European Scientific Journal, vol.10, No. 19, pp. $161-171,2014$. 